\title{
Formulation and Make-Up of Simulated Concentrated Water, High Ionic Content Aqueous Solution
}

Greg Gdowski

April 4, 1997

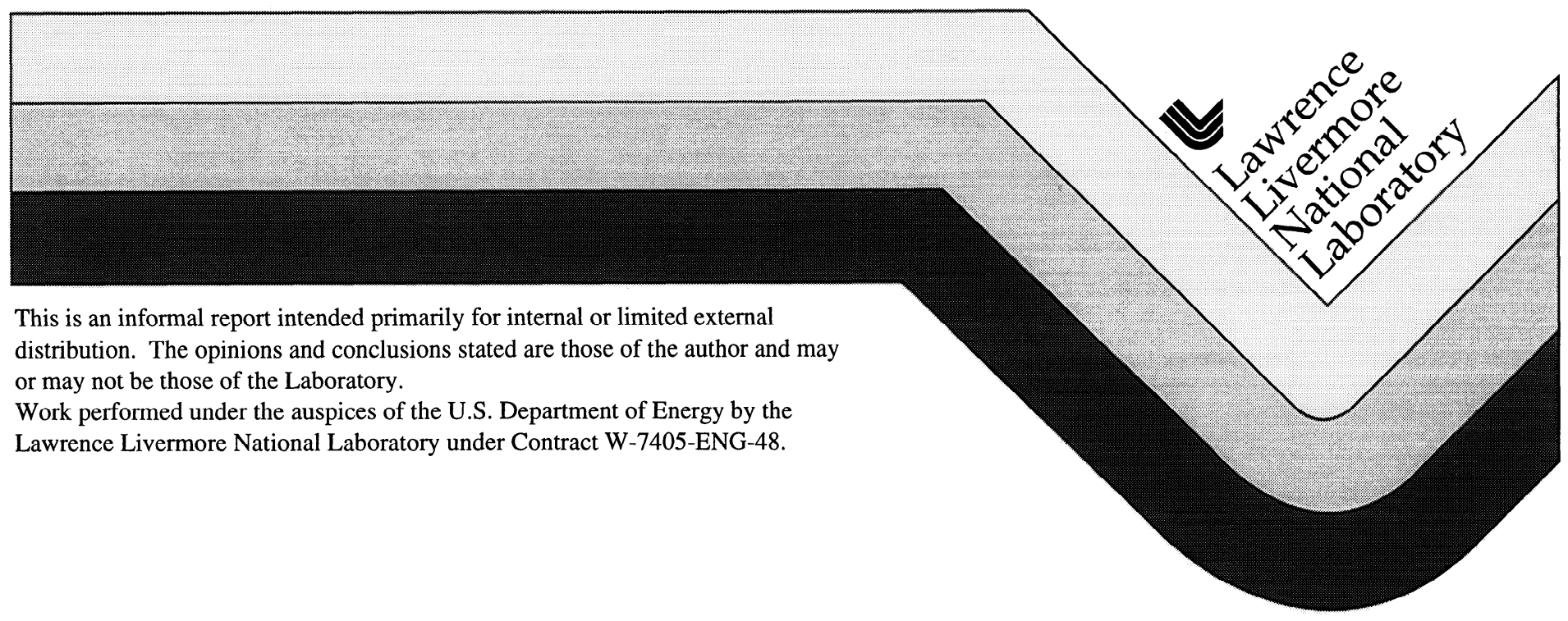




\section{DISCLAIMER}

This document was prepared as an account of work sponsored by an agency of the United States Government. Neither the United States Government nor the University of California nor any of their employees, makes any warranty, express or implied, or assumes any legal liability or responsibility for the accuracy, completeness, or usefulness of any information, apparatus, product, or process disclosed, or represents that its use would not infringe privately owned rights. Reference herein to any specific commercial product, process, or service by trade name, trademark, manufacturer, or otherwise, does not necessarily constitute or imply its endorsement, recommendation, or favoring by the United States Government or the University of California. The views and opinions of authors expressed herein do not necessarily state or reflect those of the United States Government or the University of California, and shall not be used for advertising or product endorsement purposes.

This report has been reproduced directly from the best available copy.

Available to DOE and DOE contractors from the

Office of Scientific and Technical Information

P.O. Box 62, Oak Ridge, TN 37831

Prices available from (423) 576-8401

Available to the public from the

National Technical Information Service

U.S. Department of Commerce

5285 Port Royal Rd.

Springfield, VA 22161 
University of California

Lawrence Livermore

National Laboratory

YUCCA MOUNTAIN PROJECT

Technical Implementing Procedure

Subject:

Formulation and Make-Up of Simulated Concentrated

Water, High lonic Content Aqueous Solution

No.: TIP-CM-07

Revision: $\quad$ CN TIP-CM-07-0-2

Effective Date: $\quad 04 / 04 / 97$

Page: 1 of 7

AUTHOR:

G. Gdowski

Training Required: Yes $\square \mathrm{No} \square$

Comments:

Addition of balance to acceptable list in Section 6.0; changes made in Procedure

REVISION HISTORY

Rev. No. CN No. Effective Date Description of Revision/CN

0

$0 \quad$ TIP-CM-07-0-1

$09 / 17 / 96$

0 . TIP-CM-07-0-2 04/04/97
Initial Issue

Text changes made for clarification; inclusion of previously omitted Appendix $B$; repagination.

Affects Title Page, pages 3 through 7 of 7 , and Appendices $A$ and $B$.

Addition of balance to acceptable list in Section 6.0; changes made in Procedure. Affects Title Page and pages 6 and 7 of 7 .

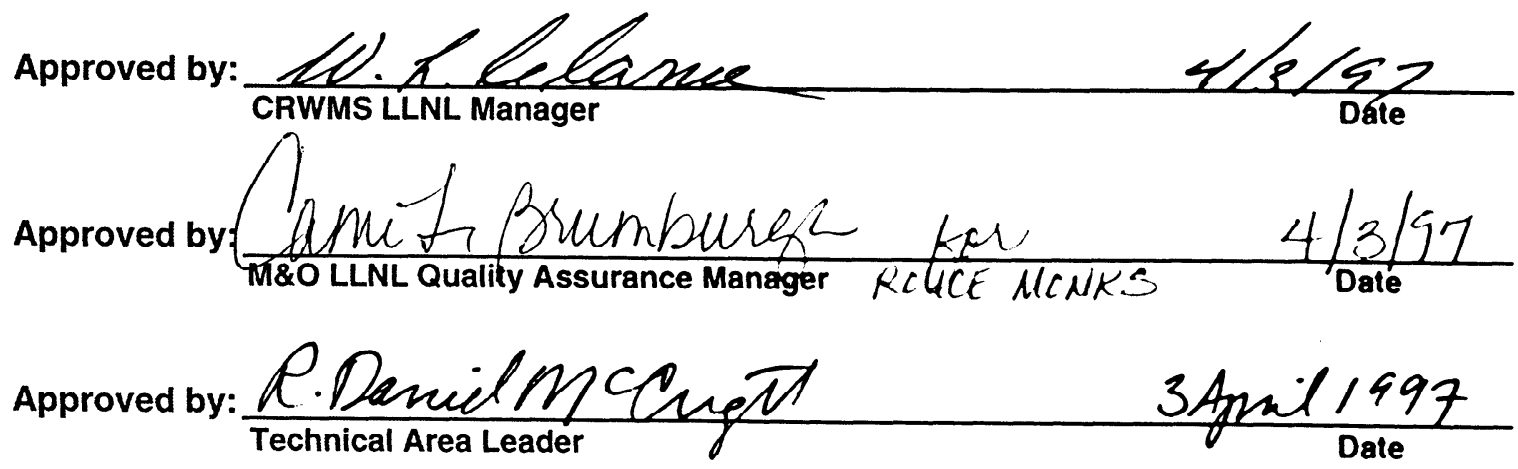




\begin{tabular}{|l|l|l|l|l|}
\hline No.: & Revision: & Pate: & Page: \\
TIP-CM-07 & 0 & $08 / 27 / 96$ & 2 & of \\
\hline
\end{tabular}

1.0 PURPOSE

This procedure describes the formulation and make-up of Simulated Concentrated Water (SCW), a high-ioniccontent water to be used for Activity E-20-50 "Long-Term Corrosion Studies." This water has an ionic content which is nominally a factor of a thousand higher than that of "representative" waters at or near Yucca Mountain. "Representative" waters were chosen as J-13 well water [Harrar, 1990] and "perched" water at Yucca Mountain [Glassley, 1996] (see Table 1). J-13 well water is obtained from ground water that is in contact with the Topopah Spring tuff, which is the repository horizon rock. The "perched" water is located in the Topopah Spring tuff, but below the repository horizon and above the water table. A nominal thousand times higher ionic content was chosen to simulate the water that would result from the wetting of salts which have been previously deposited on a container surface.

The expected composition of the SCW is given in Table 1. It is anticipated that the actual composition of test solutions will be within $\pm 20 \%$ of these values. The changes in the corrosive properties of the test solutions will be acceptable within these values. In addition similar type materials are tested in the same test vessel, so minor vessel to vessel variation of solution composition is of limited significance.

Both of the "representative" waters have similar corrosive characteristics. The solution pH's and the concentrations of the aggressive anions $\left(\mathrm{Cl}^{-}, \mathrm{F}^{-}\right.$, and $\left.\mathrm{SO}_{4}{ }^{2-}\right)$ are essentially equivalent from a corrosion stand point.

This aqueous solution is one of the four aqueous test solutions to be used in the activity. The other aqueous solutions included a Simulated Dilute Water (SDW), a simulated acidic concentrated water (SAW), and a simulated basic concentrated water (SBW).

This TIP documents the chemical reagents, reactant air, and the procedures used to make-up the aqueous solution for Activity E-20-50. More than 12,000 liters (3,170 gallons) of Simulated Concentrated Water solution are required for the test vessels for implementation of the full test matrix of the activity plan.

\subsection{SCOPE}

This procedure applies to the Simulated Concentrated Water solution, one of the aqueous solutions that are to be used in the test vessels for Activity E-20-50 "Long-Term Corrosion Studies."

\subsection{RESPONSIBILITIES}

The Principal Investigator (PI) or designee is responsible for:

- the conduct of the activities and methods described in this procedure, and

- maintaining laboratory scientific notebooks.

The Task Area Leader (TAL) is responsible for:

- ensuring that the requirements of this procedure are implemented,

- ensuring that personnel conducting the work are qualified and are trained to this procedure,

- verifying that this procedure meets the objectives of the Scientific Investigation Plan (SIP) "Metal Barrier Selection and Testing" (SIP-CM-01, Rev.3, WBS \# 1.2.2.5.1) and Activity E-20-50 "LongTerm Corrosion Studies", and

- ensuring approval of this procedure.

The YMP Quality Assurance Manager (QA Manager) is responsible for:

- $\quad$ monitoring the work to assure proper implementation of this procedure, and

- $\quad$ assuring its continued effectiveness. 


\begin{tabular}{|l|l|l|l|l|l|}
\hline No.: & $\begin{array}{l}\text { Revision: } \\
\text { TIP-CM-07 }\end{array}$ & Pate: & Page: & \\
3 & of & 7 \\
\hline
\end{tabular}

\subsection{COMPOSITION OF SCW AND REACTANT AIR}

\subsection{Aqueous Solution Composition}

The Simulated Concentrated Water (SCW) has a ionic composition that is nominally a factor of a thousand higher than that of "representative" water of Yucca Mountain. "Representative" waters were chosen J-13 well water [Harrar, 1990] and "perched" water at Yucca Mountain [Glassley, 1996]. J-13 well water is obtained from ground water that is in contact with the Topopah Spring tuff, which is the repository horizon rock. The "perched" water is located in the Topopah Spring tuff, but below the repository horizon and above the water table. The thousand times higher ionic content was chosen to simulate the water that may result from wetting of salts and minerals that have been deposited on the container surfaces.

The composition of $\mathrm{J}-13$ well water and the "perched" water are given in Table 1 . Only ions with concentration greater than $0.5 \mathrm{ppm}$ are included in this table. Minor constituents have been detected in $\mathrm{J}-13$ well water; these include $\mathrm{Li}, \mathrm{B}, \mathrm{Al}, \mathrm{Mn}, \mathrm{Fe}, \mathrm{Sr}$, and $\mathrm{PO}_{4}{ }^{3-}$ ions. These constituents have been reported in the 10-100 $\mu \mathrm{g} /$ liter concentration. The most consistently determined minor constituents are $\mathrm{Li}$ and $\mathrm{B}$ at mean (several studies) concentrations of 48 and $134 \mu \mathrm{g} /$ liter, respectively. The minor constituents are not explicitly included in the SCW. However, the reagent chemicals have some impurites, which may include the above noted impurities. The minor constituents at the reported concentrations are not expected to significantly effect the corrosion of the test specimens.

It is worth noting the differences in the "representative" waters. In terms of the calcium and bicarbonate concentrations, the "perched" water is higher in both of these constituents, and has a higher $\mathrm{pH}$; these both are probably due to contact with calcium carbonate $\left(\mathrm{CaCO}_{3}\right)$ minerals. The concentrations of $\mathrm{Na}^{+}, \mathrm{K}^{+}, \mathrm{F}^{-}$, and $\mathrm{NO}_{3}^{-}$are slightly higher in $\mathrm{J}-13$ well water.

Table 1. Compositions of "representative" Yucca Mountain waters J-13 well water and "perched" water, and the estimated composition of the simulated concentrated water.

\begin{tabular}{llll}
\hline Constituent & $\begin{array}{l}\mathrm{J}-13 \\
(\mathrm{mg} /) \\
(\mathrm{mg} /)\end{array}$ & $\begin{array}{c}\text { "Perched" } \\
(\mathrm{mg} / \mathrm{l})\end{array}$ & $\begin{array}{l}\text { Simulated Concentrated } \\
\text { Water (estimated) }\end{array}$ \\
\hline $\mathrm{Na}$ & 45.80 & 36 & 40,900 \\
$\mathrm{Si}$ & 28.5 & 37 & $27(60 \mathrm{C}) ; 49(90 \mathrm{C})$ \\
$\mathrm{Ca}$ & 13.0 & 25 & $<1$ \\
$\mathrm{~K}$ & 5.04 & 1.7 & 3,400 \\
$\mathrm{Mg}$ & 2.01 & 2.2 & $<1$ \\
$\mathrm{~F}^{-}$ & 2.18 & 0.7 & 1,400 \\
$\mathrm{Cl}^{-}$ & 7.14 & 6.3 & 6,700 \\
$\mathrm{NO}_{3}{ }^{-}$ & 8.78 & 4 & 6,400 \\
$\mathrm{SO}_{4}{ }^{-}$ & 18.4 & 15 & 16,700 \\
$\mathrm{HCO}_{3}{ }^{-}$ & 128.9 & 147 & 70,000 \\
$\mathrm{CaCO}_{3}$ & - & - & 47,500 (precipitate) \\
$\mathrm{MgCO}_{3}$ & & & 7,300 (precipitate) \\
$\mathrm{pH}$ & 7.41 & 8.1 & \\
\hline
\end{tabular}




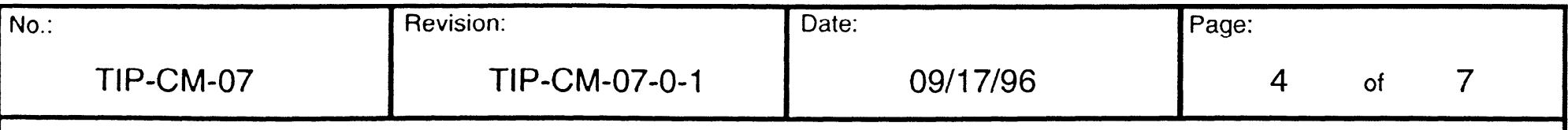

The following paragraphs explain the reasoning used to arrive at the composition and formulation of the SCW. The silica content is based on solubility of $\alpha$-cristobalite which is believed to be the dominant soluble silica phase of Yucca Mountain rock at 60 and $90^{\circ} \mathrm{C}$ [Wolery, 1983; Knauss, 1987]. Silica may be added to the solution by dissolution of sodium silicate. The salts, in general, are concentrated by a factor of a thousand over an "average" of the "representative" Yucca Mountain waters. The exceptions are calcium $\left(\mathrm{Ca}^{2+}\right)$, magnesium $\left(\mathrm{Mg}^{2+}\right)$, and bicarbonate $\left(\mathrm{HCO}_{3}{ }^{-}\right)$, which are all at lower concentration.

Previous studies have indicated that extensive concentrating of water with relative ionic concentrations like those of the "representative" water (high bicarbonate) results in the precipitation of calcium and magnesium carbonates and silica-base minerals [Drever, 1982]. Calcite $\left(\mathrm{CaCO}_{3}\right)$ will precipitate first, with some magnesite $\left(\mathrm{MgCO}_{3}\right) \mathrm{co}-$ precipitating in the calcite. The remaining magnesium will precipitate in silica-based minerals.

Simulations of concentrating the "representative" waters were run using the computer program "Geochemist's Workbend, Release 2.2" [Bethke, 1994]. The results generated were in agreement with the qualitative predictions based on the general solution composition. All of the calcium and magnesium was effectively precipitated during concentrating of the solution; a few ppm of each remained in solution.

The estimated composition of the SCW is given in Table 1. It is expected that the actual composition of test solutions will be within $\pm 20 \%$ of these values. The changes in the corrosive properties of the test solutions within these values will not be significant. In addition similar type materials are tested in the same test vessel, so minor vessel-to-vessel variation of solution composition is of limited significance.

\subsection{Reactant Air}

Reactant air is compressed building air which has been purified to remove hydrocarbons and water. Air will be purified by flowing through a Whatman Zero Air Generator (see Section 6.0). Nominal flow rates through each test vessel will be $200 \mathrm{ml} / \mathrm{min}$. Air will exit through a condenser to remove water; this greatly reduces the amount of water loss from the test vessels.

Reactant air serves two purposes: 1) it keeps the oxygen content of the vessels constant, and 2) the slightly pressurized test vessel will keep the potentially contaminated room air out of the test vessels.

\subsection{REAGENTS AND FORMULATION}

\subsection{Reagent Chemicals}

In order to obtain the solution composition given in Table 1, various combinations of chemicals can be used. A spreadsheet has been developed which calculates the composition of a solution based on the added chemicals. Copies of typical outputs of the spreadsheets are shown in Appendix $A$ for 60 and $90^{\circ} \mathrm{C}$ solutions; the amount of silica changes with temperature. Many of the chemicals listed in the spreadsheet are not used in this particular example. The inclusion of numerous chemicals in the spreadsheet allows the user the freedom to choose the needed chemicals based on availability, cost, and personal preference.

The algorithm to arrive at reagent concentrations was a trial and error method. The quantities of reagents required was estimated, and the spreadsheet calculated the total ionic content of the theoretical solution. Iteration was continued until an acceptable match was achieved.

A few guidelines were used in choosing the reagents. The choices for bicarbonate ions were $\mathrm{NaHCO}_{3}$ or $\mathrm{KHCO}_{3}$, since these are the common commercial source of bicarbonate. The use of potentially hazardous materials such as $\mathrm{HF}, \mathrm{MgF}_{2}$, and $\mathrm{CaF}_{2}$ was avoided. The more soluble salts (minerals) were chosen, for example, magnesium sulfate was chosen over the less soluble carbonate and nitrate salts. 


\begin{tabular}{|l|l|l|l|l|}
\hline No: & Revision: & Pate: & Page: \\
TIP-CM-07 & TIP-CM-07-0-1 & $09 / 17 / 96$ & 5 & of \\
\hline
\end{tabular}

Also solution silica will be obtained by the addition of sodium silicate. (Calculations showed that dissolution of solid silica phases would take extended periods of time (>1000 days) in order for sufficient amounts of silica to dissolve.) Note using sodium silicate will result in slightly elevated sodium concentrations.

Using sodium silicate will result in the formation of hydroxyls equal to the number of moles of sodium atoms added. In order to neutralize the hydroxyls, an equal number of moles of acid (hydrochloric, nitric, or sulfuric) will be added.

Since a large percentage of both the calcium and magnesium will form carbonate precipitates, it was not necessary to add soluble salts of these ions to the level of the concentrating. However excess of these ions will be added such that precipitates of calcite and magnesite will form.

A word of caution in using the spreadsheet: the calculations assume that the chemicals dissolve completely and may therefore over estimate the composition of some species. The user must therefore be aware of potential solubility problems. A listing of the solubilities of various chemical is shown in Appendix B.

A typical example of chemicals used to make-up of the aqueous solution are listed in Table 2 along with the quantities required per 1000 l of solution.

Table 2. An example of the reagents and quantites required per 1000 liters of simulated aqueous solution.

\begin{tabular}{lcc}
\hline Reagent & $\begin{array}{l}\text { Quantity @ } 60^{\circ} \mathrm{C} \\
\text { (gms / } 1000 \text { liters) }\end{array}$ & $\begin{array}{l}\text { Qualtity @ 90 } \\
\text { (gms / } 1000 \text { liters) }\end{array}$ \\
\hline $\mathrm{NaHCO}_{3}$ & $128,450.0$ & $128,297.0$ \\
$\mathrm{NaF}$ & $3,182.6$ & $3,182.6$ \\
$\mathrm{Na}_{2} \mathrm{SO}_{4}$ & $12,236.4$ & $12,254.5$ \\
$\mathrm{Na}_{2} \mathrm{SiO}_{3} \cdot 5 \mathrm{H}_{2} \mathrm{O}$ & 204.0 & 370.0 \\
$\mathrm{MgSO}_{4} \cdot 7 \mathrm{H}_{2} \mathrm{O}$ & $21,392.0$ & $21,392.0$ \\
$\mathrm{CaCl}_{2} \cdot 2 \mathrm{H}_{2} \mathrm{O}$ & $7,598.0$ & $7,598.0$ \\
$\mathrm{Ca}\left(\mathrm{NO}_{3}\right)_{2} \cdot 4 \mathrm{H}_{2} \mathrm{O}$ & $12,168.5$ & $12,168.5$ \\
$\mathrm{HCl}$ & 3.73 & 70.1 \\
$\mathrm{KCl}$ & $6,417.8$ & $6,282.0$ \\
$\mathrm{KHCO}_{3}$ & 10.4 & 192.5 \\
$\mathrm{CaCO}_{3}$ & $37,117.3$ & $37,117.3$ \\
$\mathrm{H}_{2} \mathrm{SO}_{4}$ & 89.3 & 76.79 \\
\hline
\end{tabular}




\begin{tabular}{|l|l|l|l|l|}
\hline No.: & Revision: & Page: & \\
TIP-CM-07-0-2 & & $04 / 04 / 97$ & 6 & of \\
\hline
\end{tabular}

The chemicals and the quantities used in making up the test solutions will be listed in the Scientific Notebook or electronic media.

\subsection{Purified Water}

The make up of the test solutions requires large quantities of low ionic content water is required. The use of LLNL de-ionized water is acceptable. This water has an ionic content typically less than $1 \mathrm{ppm}$. This is less than $0.001 \%$ of the ionic content due to the added chemicals. The source of the water used in testing will be recorded in the scientific notebook.

\subsection{Reactant Gas}

The reactant air will be purified before entering the test vessels.

\subsection{EQUIPMENT}

A balance that can measure to 0.1 grams is acceptable for make-up of the test solutions. An acceptable balance is:

\section{Mettler Balance Model \# AT200 \\ Serial Number 1114463500 \\ Mettler Balance Model \# PC16 Serial Number A51361}

An air purifier for cleaning the building compressed air is required. The following unit or equivalent is acceptable:

Whatmann Type 76-818NA Zero Air Generator

Unit Serial Number 768180065B

Tower Module Serial Number 76811-10116B

This air purifier removes hydrocarbon to $0.1 \mathrm{ppm}$.

\subsection{PROCEDURE}

The following procedure will be followed in making-up of the Simulated Concentrated Water solutions for the test vessels:

1) Purified water is emplaced in the cleaned vessel; the liquid level is slightly less than the required depth for testing. (Need to account for rise in water level due to the specimens and racks, and the density decrease due to raising the water temperature to the test temperature.)

2) The amount of purified water added to the test vessels is estimated.

3) The required amounts of reagent chemicals is determined and entered in the scientific notebook or electronic media.

4) The purified water is heated to a nominal temperature of $40^{\circ} \mathrm{C}$. This will accelerate reactions that occur in solution.

5) The water will be stirred. The stirrer mounted on the vessel is sufficient. 
No:

TIP-CM-07 $\quad$\begin{tabular}{r|l} 
Revision: & Date: \\
TIP-CM-07-0-2 &
\end{tabular}

6) Add chemicals to water. No particular order is required for chemical additions except that sulfuric acid will be the last chemical added to the test vessel.

7) Concentrated sulfuric acid shall be diluted 500-1000 times the required volume using deionized water and then added to the test vessel.

8) The vessel is sealed and brought to testing temperature for at least 24 hours.

9) The specimen racks are inserted into test vessel.

10) A sample of the test solution is withdrawn for analysis approximately a day after the level of water reaches the normal operation set point.

Note: The liquid level in the test vessels will self-adjust to the required level. If the liquid level is low, the liquid level control system will add purified water. If the liquid level is high, water removal by the air purge will occur; this may be slow but it will occur. It is preferred to add water rather than to remove water, since the control system shuts down the heaters when the liquid level is above a certain height.

8.0 QA RECORDS

Any data that is pertinent to this TIP shall be entered into the Scientific Notebook or electronic media for Activity E-20-50. This shall include, but is not be limited to the chemical used lot \# manufacturer supplied analysis, and actual reagent chemical amounts used for make-up.

9.0

REFERENCES

C.M. Bethke, The Geochemist's Workbench. Version 2.0; A Users Guide to Rxn. Tact. React, and Gtplot, Hydrogeology Program, University of Illinois, 1994.

J.I. Drever, The Geochemistry of Natural Waters, Prentice-Hall, Inc., Englewood Cliffs, NJ, 1982.

W. Glassley, private communication, 1996.

J.E. Harrar, J.F. Carley, W.F. Isherwood, and E. Raber, "Report of the Committee to review the Use of J-13 Well Water in Nevada Nuclear Waste Storage Investigations," Lawrence Livermore National Laboratory report UCID21867, Livermore California, January 1990.

K.G. Knauss, W.J. Beiriger, D.W. Peifer, "Hydrothermal Interaction of Solic Wafers of Topopah Spring Tuff with J13 Water at 90 and $150^{\circ} \mathrm{C}$ Using Dickson-Type, Gold-Bag Rocking Autoclaves: Long-Term Experiments," Lawrence Livermore National Laboratory Report UCRL-53722, May 1987.

T.J. Wolery, Memo GCC-83-3/1773w, "Summary of Silica Solubilty Data for Acid-to-Neutral pH Conditions," 16 Nov. 1983. 


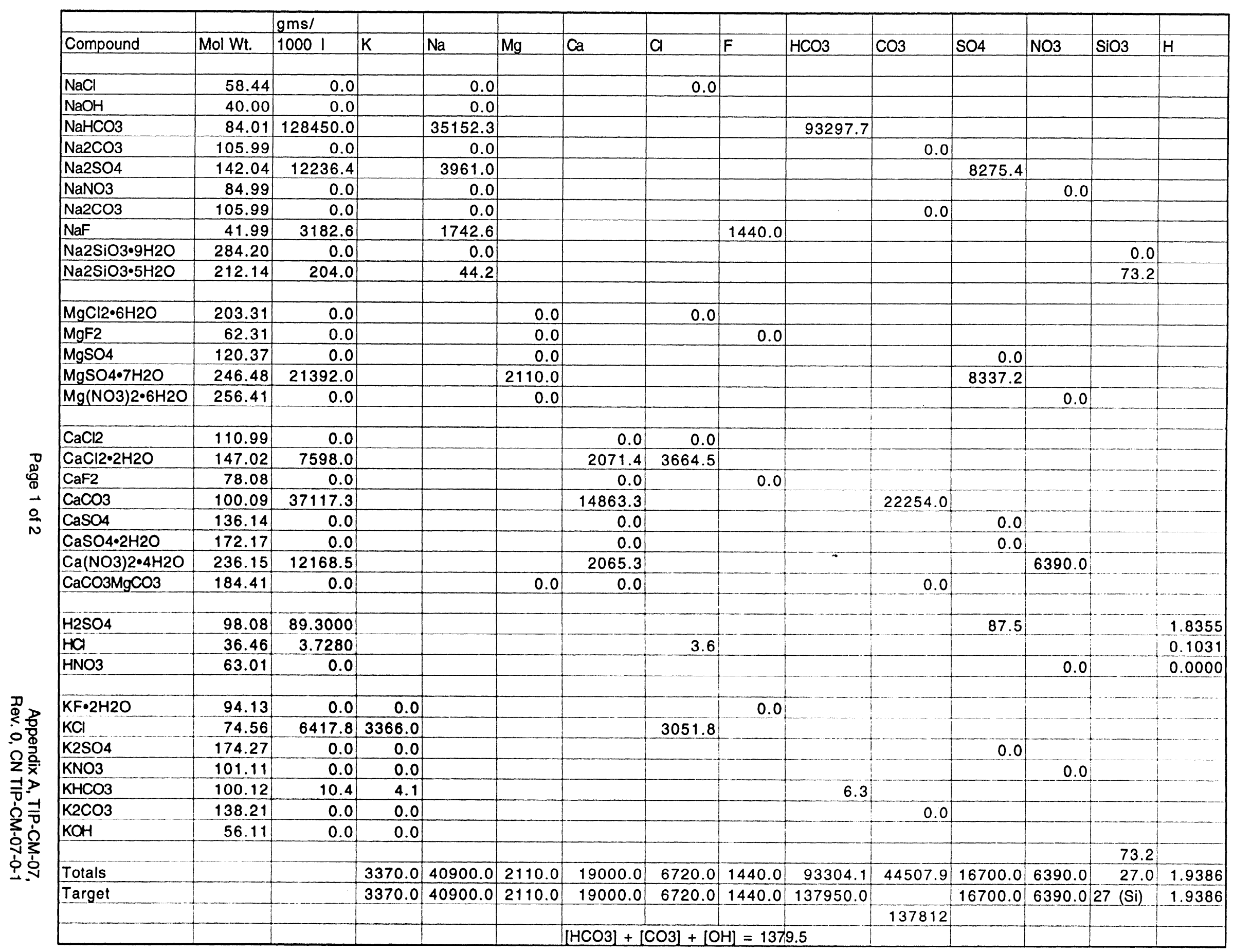




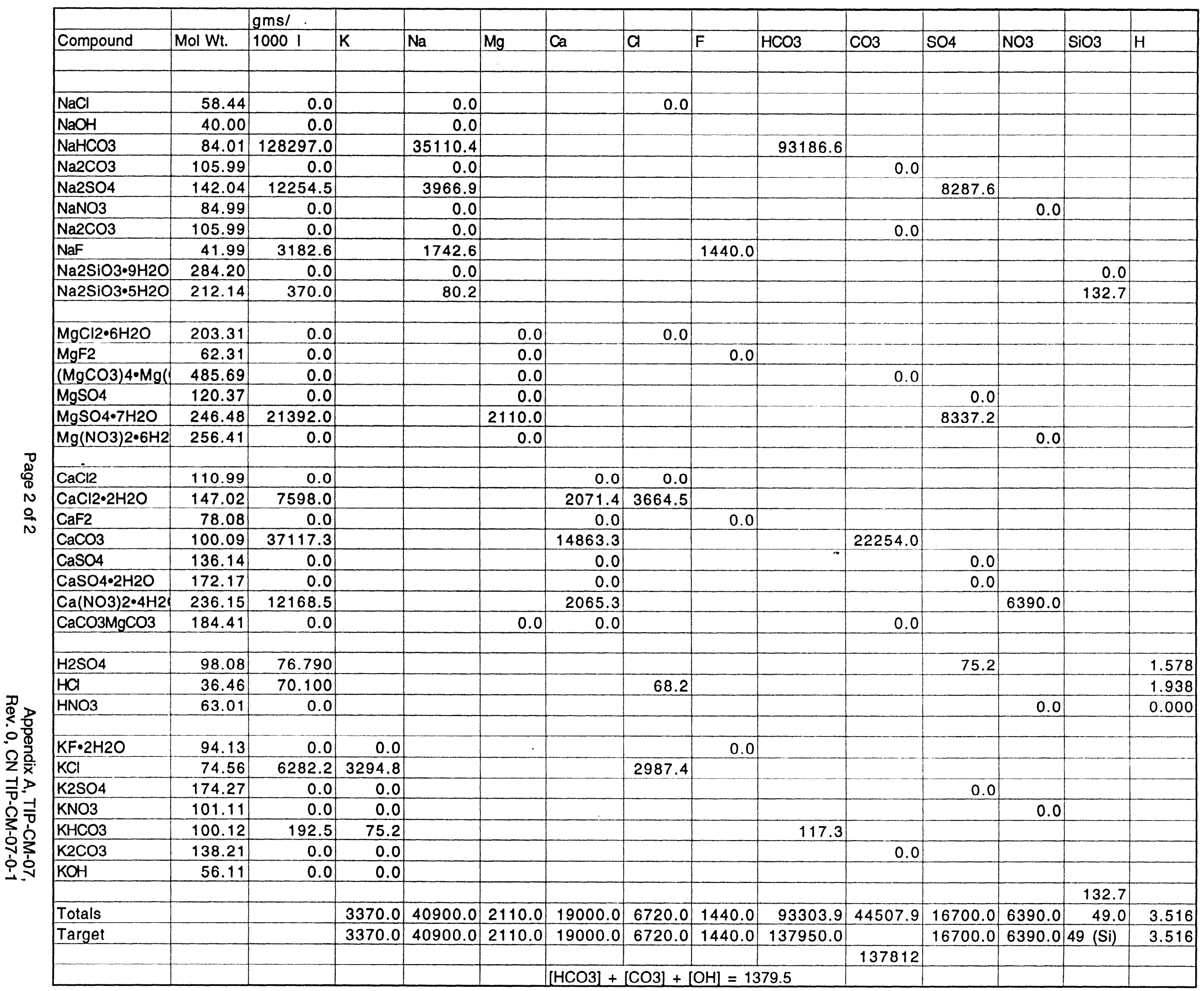


Appendix B. Solubilites in Water

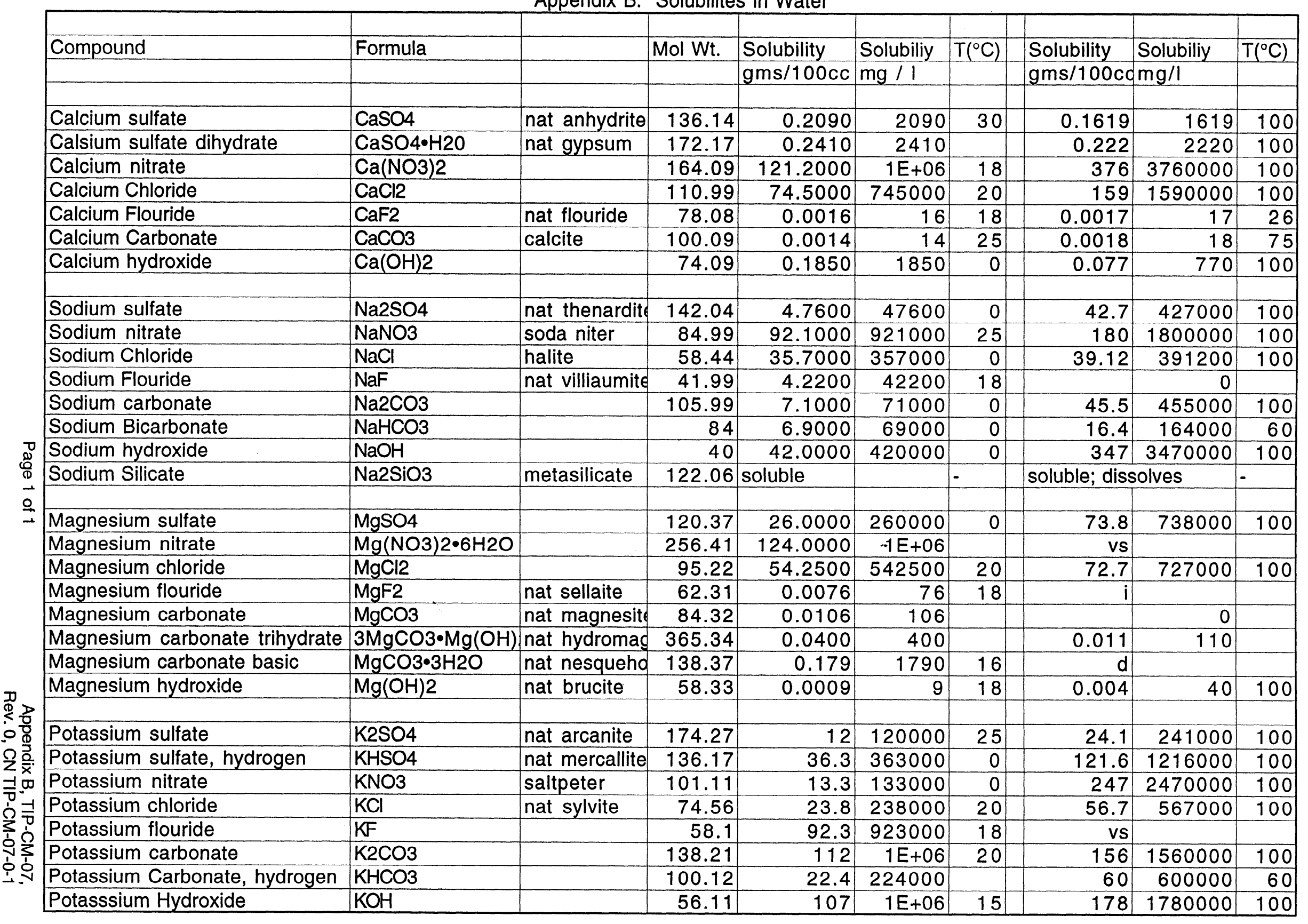

Source: CRC Handbook of Chemistry and Physics, R.C. Weast, M.J. Astle, eds., CRC Press, Inc., Boca Raton, FL, 1981. 